NASA Technical Memorandum 101982

\title{
Identification of Space Shuttle Main Engine Dynamics
}

\author{
Ahmet Duyar \\ National Aeronautics and Space Administration \\ Lewis Research Center \\ Cleveland, Ohio \\ Ten-Huei Guo \\ Sverdrup Technology, Inc. \\ NASA Lewis Research Center Group \\ Cleveland, Ohio \\ and \\ Walter C. Merrill \\ National Aeronautics and Space Administration \\ Lewis Research Center \\ Cleveland, Ohio
}

Prepared for the 1989 American Control Conference cosponsored by the AIAA, ASME, IEEE, AIChE, AISE, ISA, and SCS Pittsburgh, Pennsylvania, June 21-23, 1989 


\section{ORIGINAL PAGE IS OF POOR QUALITY}

Ahmet Duyar*

National Aeronautics and Space Administration

Lewis Research Center

Cleveland, Ohio 44135

Ten-Hue i Guo

Sverdrup Technology Inc.

NASA Lewis Research Center Group

Cleveland, Ohio 44135

Walter C. Merrill

National Aeronautics and Space Administration

Lewis Research Center

Cleveland, Ohio 44135
ABSTRACT

System identification techniques are used to represent the dynamic behavior of the Space Shuttle Main Engine. The transfer function matrices of the linearized models of both the closed loop and the open loop system are obtained by using the recursive maximum likelihood method.

\section{NOMENCLATURE}

\section{$A, B, C$ state space matrices}

a denominator polynomial of the transfer function matrix

b numerator polynomial of the transfer function matrix

D signal duration, sec

e equation error

$f \quad$ frequency, rad/sec

$H . H_{i j}$ system transfer function matrix and its
$i, j$ th element

MR oxygen to fuel mixture ratio of the main combustion chamber

n discrete time integer

$N \quad$ number of samples

P pressure, psi

s speed, rpm

$T$ temperature, ${ }^{\circ} \mathrm{R}$

$t$ time, sec

tc clock time, sec

$u, x, y$ input, state and output vectors

$z \quad z$ transform variable

- Summer Faculty Fellow in 1988; presently at Mechanical Engineering Dept., Florida Atlantic University, Boca Ratan, Florida 33432.
Greek Symbols

Su deviation of input from nominal

$\delta x \quad$ deviations of state from nominal

Sy deviations of output from nominal

$\theta$ valve actuator output rotary motion. dimensionless

\section{Subscripts}

CCV coolant control valve

C chamber

FPOV fuel preburner oxidizer valve

HPFT high pressure fuel turbine

HPOT high pressure oxidizer turbine

$\max \quad \operatorname{maximum}$

min minimum

MFV main fuel valve

MOV main oxidizer valve

OPOV oxidizer preburner oxidizer valve

$R$ request

\section{INTRODUCTION}

Accurate representation of the dynamic behavior of the Space Shuttle Main Engine (SSME) is required for a variety of diagnostic and control design and evaluation purposes. A complete. nonlinear dynamic simulation has been developed (Rocketdyne Division of Rockwell International Corporation, 1981). However, its size and complexity make it very difficult to use for design purposes. This paper describes the identification of linearized dynamic models of the SSME from the nonlinear dynamic simulation. The identified linearized models are valid in limited response regions about the operating point corresponding to the 100 percent power level. They are suitable for the purpose of control system design and development. 
Initially a brief description of the SSME is given. This is followed by a description of the identification process and the model used. Finally, some results obtained from the identified models are compared with the results obtained from the nonlinear simulation for the same input.

\section{THE SPACE SHUTTLE MAIN ENGINE}

Different aspects of the SSME as well as its principle of operation are described in the literature (Landaver, 1988; Klatt et al., 1982). A brief descriotion of the main engine is given below by following them.

The space shuttle orbiter main propulsion system is composed of three space shuttle main engines. The engines use liquid oxygen and liquid hydrogen propellants that are carried in an external tank attached to the orbiter. These elements and the two strap-on solid propellant rocket motors are assembled in the vertical position. (Solid rocket boosters and the SSMEs provide the thrust for the first portion of the flight until the solid propellant motors burn out and are separated.) The SSME's continue to burn until the vehicle is near the desired orbital velocity. Following SSME shutdown, the external tank is separated and final orbit insertion is accomplished by the orbital maneuvering system. After completing orbital operations, the orbiter reenters the atmosphere and $\mathrm{glides}$ to a landing The engines operate for a total of $480 \mathrm{sec}$ from launch. Each produces a sea level thrust of 375000 ib and a vacuum thrust of 47000016 To understand the overall flow of fuel and oxidizer to produce the thrust, a schematic diagram of the propellant flows and the control valves is shown in Fig. 1

Pressurized fuel, provided by the fuel tank flows through the low pressure fuel pump and the high pressure fuel pump, is fed to the regenerative cooling and the preburners. A pressurized oxidizer tank provides the oxidizer. It flows through the low pressure oxidizer pump, to the high pressure oxidizer pump where the output flow splits as shown in Fig. 1 .

The two high pressure turbines are driven by a fuel turbine preburner and an oxidizer turbine preburner, each of which produces hot gas. The low pressure turbines are driven from the high pressure pump flows. The fuel from the high pressure fuel pump (HPFP) goes through the ma in fuel valve (MFV). After the MFV, the flow divides into fixed nozzle cooling flow, main chamber cooling flow, and coolant control valve (CCV) flow. The relative proportions of these three flows is determined by the CCV. Heat is absorbed from the combustion chamber nozzle and the fuel flows to the preburners where combustion and pressure is controlled by the fuel preburner oxidizer valve (FPOV) and the oxidizer preburner oxidizer valve (OPOV). In the fixed nozzle cooling, the coolant control valve determines the percentage of the fuel used for cooling the combustion chamber by establishing a bypass flow direct from inlet to discharge.

The high-pressure fuel rich hot gas from the preburners goes through the two high-pressure turbines and returns through the hot gas manifolds to the fuel injector (FI) of the combustion chamber. Main chamber cooling fuel flow powers the low pressure fuel turbine (LPFT) and returns directly to the fuel injector of the main combus tion chamber.

Oxidizer from the high pressure oxidizer pump (HPOP) solits into three paths. Flow frcm the first path drives the low-pressure oxidizer turbine (LPOT). The output flow from the LPOI merges with the output of the low pressure oxidizer pump (LPOP). The second flow goes through the main oxidizer valve (MOV) to the oxidizer injector (OI) in the combustion chamber. The third flow enters the preburner oxidizer pump (PBOP) and is divided between the preburners as determined by the FPOV and the OPOV. This completes the flow paths for turbine drive and control.

\section{THE CONTROL SYSTEM OF THE SSME}

The existing control system of the SSME utilizes five valves FPOV, OPOV. MFV, MOV, and CCY to control the mixture ratio and the main chamoer pressure which is correlated with the thrust. Open and closed loop control of these valves are used to accomplish the SSME mission. A typical SSME mission is shown in Fig. 2

All the valves are initially scheduled to follow the start sequence as indicated in Fig. 3 . During the main stage, the thrust and the mixture ratio are controlled by adjusting the OPOV and FPOV valves. This adjustment is based on thrust and mixture ratio request, through a closed loop proportional plus integral feedback control. A conceptual block diagram of the control system during the main stage of operation is shown in Fig. 4 .

For the purpose of model identification the following inputs and outputs are used. The closed loop system inputs are the mixture ratio request, $M R_{R}$, and the chamber pressure request, $P_{C R}$, which is proportional to the thrust. The open loop system inputs are the angular displacements of the valve actuators for each of the five valves, ӨOPOV. ӨfPOV, ӨCCV, $\theta_{M O V}$, ӨMFV. The outputs are the chamber pressure $\left(P_{C}\right)$, HPFT pressure (PHPFT), HPOT pressure (PHPOT), HPFT temperature (THPFT), HPOT temperature (THPOT), mixture ratio (MR), HPFT speed (SHPFT), and HPOT speed (SMPOT). In this study all parameters are normalized and expressed as the fractional deviations from the nominal operating condition.

\section{SYSTEM IDENTIFICATION}

Identification may be defined as the determination of the mathematical model of a process among a class of mathematical models based on the measurements of input and output data of the process. Hence, the steps in identification consist of: determining a priori knowledge, selection of a driving signal that contains enough spectral components to excite all modes of the system, selection of a model, and parameter estimation. These steps are followed in the identification of SSME dynamics and are outlined below.

\section{A Priori Knowledge}

The responses of both the closed and the open loop system for test input signals are examined to obtain preliminary information about the types of nonlinearities and the bandwidth of 


\section{ORIGINAL PAGE IS \\ OF POOR QUALITY}

these systems. The responses of the closed loop system and some of the selected outputs of the open loop system as well as the test input signals are shown in Figs. 5 to 7.

The closed loop response, as shown in Fig. 5, indicates existence of both the stiction and backlash type of nonlinearities and a small system bandwidth of approximately $5 \mathrm{~Hz}$. The backlash nonlinearity is more obvious from the response of the open loop system, since the outputs cannot return to their initial values when the step input is removed, as shown in $\mathrm{Fig} .6$. Figure 7 indicates that CCV. MOV, and MFV valve actuator angular displacements are essentially decoupled from the outputs. Therefore at this nominal operating condition only the actuator angular displacements of the valves FPOV and OPOV are used as the inputs of the open loop system.

\section{Selection of a Driving Signal}

In this study. a pseudo random binary sequence (PRBS) is selected as the input perturbation signal of the system because of its convenience and its suitability for similar applications (Cottington and Pease, 1978, Sudhakar et al., 1988). A PRBS is a wideband, long-duration signal which possesses one of two values. The signal switches from one value to another at time intervals determined by a clock. A PRBS is easily generated using shift registers or a computer program, and can be made small enough amplitude so as not to significantly alter the operating condition of the engine and yet still yield useful information for identification. The amplitude of the PRBS signal used in this work is 2 percent of the nominal operating point magnitude of the chosen input.

The clock time, $t_{c}$, is chosen to be in the range of system time constants as follows. The minimum and the maximum observed frequencies, $f_{\min }$ and $f_{\max }$, are estimated by examining the response of both the closed loop and the open loop system from Figs. 5 and 6 . Then the clock time, $t_{c}$, and the number of samples needed are determined by using the estimated values of the minimum and the maximum frequencies using the equations below:

$$
\begin{gathered}
t_{c}=\frac{1}{2 f_{\max }} \\
D=\frac{1}{f_{\min }} \\
N=\frac{D}{t_{c}}
\end{gathered}
$$

where $D$ is the signal duration and $N$ is the number of samples. For the identification of the open loop system, a clock time of $0.04 \mathrm{sec}$ and 511 samples are used. This corresponds to a maximum frequency of $78.5 \mathrm{rad} / \mathrm{sec}(12.5 \mathrm{~Hz}), \mathrm{a}$ minimum frequency of $0.31 \mathrm{rad} / \mathrm{sec}(0.05 \mathrm{~Hz})$ and a signal duration of $20.44 \mathrm{sec}$. A step input is used as the driving signal for the closed loop system since its response is very slow, as shown in Fig. 5.
Selection of a Mathematical Model

As mentioned earlier, Figs. 5 and 6 indicate the existence of significant backlash and stiction nonlinearities associated with the valve dynamics. It is assumed that these two nonlinearities can be isolated from the rest of the system as shown in Fig. 8. Here, the cpen loop system includes actuator dynamics, the nonlinear element which contains valve stiction and valve linkage backlash, and the engine system which includes all other nonlinearities and the engine dynamics. To simplify the analysis, the backlash and stiction were removed from the simulation. All subsequent results are obtained with these two nonlinearities removed. Now the open loop system, without the backlash and the stiction, was 1 inearized and identified. The backlash and the stiction nonlinearities can later be added to the identified system. In practice values for backlash and stiction would be determined from manufacturer's specifications or bench testing of the individual components.

The open loop dynamics of the SSME can be described by the nonlinear equations:

$$
\begin{gathered}
x(t)=f[x(t), u(t)] \\
y(t)=g[x(t)]
\end{gathered}
$$

where $x, u$, and $y$ are the state, the control, and the output vectors. Linearizing these equations about a nominal operating condition and discretizing yields:

$$
\begin{gathered}
\delta x(n+1)=A \delta x(n)+B \delta u(n) \\
\delta y(n)=C \delta x(n)
\end{gathered}
$$

where $\delta x, \delta u$, and $\delta y$ are the deviations of the state, the input and the output vectors, respectively, about the nominal operating condition. Taking the z-transform of Eqs. (6) and (7), the linear system model relating the input vector su and the output vector $\delta y$ can be obtained as:

$$
\delta y(z)=H(z) \delta u(z)
$$

where

$$
H_{i j}(z)=C_{i}(z I-A)^{-1} B_{j}
$$

Here, $C_{j}$ is the $i$ th row of the $C$ matrix and $B_{j}$ is the $j$ th column of the $B$ matrix. A parameter estimation algorithm can be used to obtain the parameters of each of the elements of the transfer function matrix, $\mathrm{H}_{i j}(\mathrm{z})$.

\section{Parameter Estimation Algorithm}

The recursive maximum likelihood (RML) algorithm (Eykhoff, 1981) is used to estimate the parameter values. It computes the coefficients of the transfer function between an input and an output. That is, if $\delta u_{j}(n)$ and $\delta y_{1}(n)$ are the input and output of a linear time invariant system, $H_{1}(z)$, then the RML algorithm determines $H_{1}(z)$ from the data $\delta u_{j}(n)$ and $\delta y_{j}(n)$ for some range of time $n$. $H_{11}(z)$ is found by minimizing the total energy of the so called equation error: 


$$
\begin{gathered}
e(z)=a(z) \delta y_{1}(z)-b(z) \delta u_{1}(z) \\
H(z)=\frac{b(z)}{a(z)}
\end{gathered}
$$

Cenerally, the RML algorithm needs fewer data samples or parameter estimation than other approaches and can account for the presence of certain types of noise. It can be modified to track slowly time varying parameters and can be extended to the analysis of multi-input multisutout systems (Eykhoff, 1981, Ljung and Soderstorm, 1985).

The RML method estimates the parameters of a model when its order is known. However, the determination of the order of a model is still an open oroblem (Ljung and Soderstorm, 1985). The method employed here is based on the "Parsimony principle." In this method parameters are estimated for models of increasing orders. The estimate of the final error norm is computed for each, and the order for which the decrease in error is no longer appreciable is adopted (Box and Jenkins, 1970). Thus, from the error plot, which plots error versus order of the model, the optimum order is chosen as the one corresponding to the "knee" of the error plot. A typical error plot is shown in Fig. 9.

The output of the nonlinear simulation for PRBS input perturbations is used to determine the transfer function matrix of the linearized model by utilizing the RML algorithm. Each transfer function matrix element is determined by utilizing the response of the system to small perturba.. tions about a nominal operating point as follows. The ith element of the input vector is perturbed and applied to the system with other elements of the input vector set at their nominal values to obtain the perturbed outputs. By subtracting the nominal values from the perturbed ralues, the differential input $\delta u_{j}(n)$, and the corresponding outputs $\delta y_{j}(n)$, for $i=1,2,3$, are obtained. This procedure is repeated for all the inputs.

The RML algorithm outlined before is available in a software package called Ctri-C (Systems Control Technology, 1986), and is utilized to estimate the parameters of the model. Since the nonlinear simulation is used as the unknown system, the system is assumed to be noiseless. Under this condition the RML method simplifies to the recursive least squares method.

\section{RESULTS}

The procedure outlined earlier is used to identify both the closed loop and the open loop system. The responses of the identified model are compared with the responses obtained from the nonlinear simulation for the same input and observed to be in good agreement as shown in Figs. 10 and 11 . The parameters of the elements of the transfer function matrix are given in Table 1 .

The responses of the open loop system are also compared with the responses obtained from the nonlinear simulation. A typical result is shown in Fig. 12. In general, it is observed that the gains for positive and negative perturbation signals are significantly different. In order to compensate for this phenomenon, a system gain with different values for positive and negative perturbations is added to the linearized model. In fact it is this ratio of the magnitudes of the positive and negative values which must be identified. This ratio is equal to the ratio of the magnitudes of the positive and negative steady state values of the outputs obtained from the nonlinear simulation. One model that includes this variable system gain can be expressed mathematically as:

$$
\delta y(z)=H(z) \delta u^{*}(z)
$$

$$
\delta u^{*}(k)=\begin{array}{ll}
\alpha \delta u(k) & \delta u(k) \geq 0 \\
(2-\alpha) \delta u(k) & \delta u(k) \leq 0
\end{array}
$$

The identification procedure is carried out with this modified PRBS and a piecewise linear model is obtained. Comparison of the responses of this model with the responses of the nonlinear simulation showed excellent agreement as shown in Figs. 13 to 16 . The parameters of the coefficients of the transfer function matrix as well as the values of $\alpha$ are given in Table 2 . The proposed model block diagram structure is given in Fig. 17.

\section{CONCLUSION}

System identification techniques are used to represent the dynamic behavior of the SSME. The comparison of the responses of the nonlinear simulation with the responses of the identified model indicates very good agreement. The identified model can be used for control design purposes.

The identified model does not include valve linkage backlash and valve stiction nonlinearities. These nonlinearities should be added to the identified model and the validity of the model should be checked by comparing it with the full nonlinear simulation.

The identified model is valid for a limited response region about the 100 percent power level operating condition. This study will be extended so as to obtain models at other operating cond:tions. Then these point models can be linked to cover the full range of operation of the SSME.

\section{REFERENCES}

Box, G.E.P. and Jenkins, G.M., 1970, Time Series Analysis: Forecasting and Control, Holden Day, San Francisco.

Cottington, R.V. and Pease, C.B., 1979, "Dynamic Response Testing of Gas Turbines," Journal of Engineering for Power, Vol. 101 pp. 95-100

Eykhoff, Pieter, 1974, System Identification: Parameter and State Estimation, John Wiley and Sons, New York.

Klatt, F.P. and Wheelock, V.J., 1982, "The Reusable Space Shuttle Main Engine Prepares for Long Life," Shuttle Propulsion Systems; Proceedings of the Winter Annual Meeting,

J.W. Robinson, ed., ASME, N.Y. pp. 33-44.

Landaver, J. Paul, 1988, "Real Time Simulation of the Space Shuttle Main Engine on the SIMSTAR Multiprocessor, "Aerospace Simulation III; Proc. of the SCS Multiconference, Monte Ung, ed. Society for Computer Simulation, pp. 286-298. 
Ljung, Lennart and Soderstorm, Torsten,

1983. Theory and Practice of Recursive Identification, MIT Press, Cambridge, Mass.

Rockwell International Corporation, 1981. "Engine Balance and Dynamic Model," Report FSCM No. 02602, Spec. No. RL00001.

Rockwell International Corporation, 1988. "SSME Engine, Redline and Control Overview,"

Report 80 88-62.
Sudhakar, R. Duyar, A. and Ahmadvand, i. 1988. "'System Identification of Gas Turbines," Submitted to ASME Winter Annual Meeting. Chicago. Illinois.

System Control Technology, 1986, Control-C Users Guide.

TABLE 1. - IDENTIFIED MODEL PARAMETERS

FOR THE CLOSED LOOP SYSTEM

$\left[H_{i f}(z)=\frac{b_{1} z^{-1}+b_{2} z^{-2}+b_{3} z^{-3}+b_{4} z^{-4}}{1+a_{1} z^{-1}+a_{2} z^{-2}+a_{3} z^{-3}+a_{4} z^{-4}}\right]$

\begin{tabular}{|c|r|c|c|c|}
\hline Input & \multicolumn{2}{|c|}{$P_{C R}$} & \multicolumn{2}{c|}{$M_{R}$} \\
\hline Output & \multicolumn{1}{|c|}{$P_{C}$} & $M R$ & $P_{C}$ & \multicolumn{1}{c|}{ MR } \\
\hline Parameter & & & & \\
$a_{1}$ & -1.048 & 0 & 0 & -1.025 \\
$a_{2}$ & .285 & & & .325 \\
$a_{3}$ & .102 & & & -.223 \\
$a_{4}$ & -.134 & & & 0 \\
$b_{1}$ & -.008 & & & .017 \\
$b_{2}$ & .272 & & & .336 \\
$b_{3}$ & .053 & & & -.276 \\
$b_{4}$ & -.113 & & & 0 \\
\hline
\end{tabular}

TABLE 2. - IDENTIFIED MODEL PARAMETER FOR THE OPEN LOOP SYSTEM

$$
\left[H_{i j}(z)=\frac{b_{1} z^{-1}+b_{2} z^{-2}+b_{3} z^{-3}+b_{4} z^{-4}}{1+a_{1} z^{-1}+a_{2} z^{-2}+a_{3} z^{-3}+a_{4} z^{-4}}\right]
$$

(a) Input $=$ OOPOV

\begin{tabular}{|c|c|c|c|c|c|c|c|c|}
\hline Output & $P_{C}$ & $P_{H P F T}$ & $P_{\text {HPOT }}$ & THPFT & $T_{\text {HPOT }}$ & MR & SHPFT & SHPOT \\
\hline $\begin{array}{l}\alpha \\
d_{1} \\
d_{2} \\
d_{3} \\
b_{1} \\
b_{2} \\
b_{3}\end{array}$ & $\begin{array}{l}0.88 \\
-.676 \\
.0373 \\
0.0517 \\
.0517 \\
. .4947\end{array}$ & $\begin{array}{l}0.88 \\
-.708 \\
.0602 \\
0 \\
.1093 \\
.4627 \\
0^{.462}\end{array}$ & $\begin{array}{l}0.89 \\
-.787 \\
.0985 \\
.0183 \\
.5358 \\
.0086 \\
.0925\end{array}$ & $\begin{array}{l}0.85 \\
-.821 \\
.16 \\
.0151 \\
-.117 \\
.914 \\
-.533\end{array}$ & $\begin{array}{l}0.94 \\
-.457 \\
.0151 \\
.0448 \\
2.911 \\
-.429 \\
-.004\end{array}$ & $\begin{array}{l}0.9 \\
-.526 \\
.04 \\
0 \\
.0555 \\
.4975 \\
0 .\end{array}$ & $\begin{array}{l}0.87 \\
-.998 \\
.252 \\
0 \\
.0092 \\
.1416 \\
0 .\end{array}$ & $\begin{array}{l}0.89 \\
-.501 \\
-.023 \\
0 \\
.2164 \\
.4698 \\
0 .\end{array}$ \\
\hline
\end{tabular}

(b) Input $=\theta_{F P O V}$

\begin{tabular}{|c|c|c|c|c|c|c|c|c|}
\hline Output & $P_{C}$ & $P_{\text {HPF T }}$ & $P_{\text {HPOT }}$ & THPFT & $T_{H P O T}$ & MR & SHPFT & SHPOT \\
\hline $\begin{array}{l}\alpha \\
a_{1} \\
a_{2} \\
a_{3} \\
b_{1} \\
b_{2} \\
b_{3}\end{array}$ & $\begin{array}{c}\text { N/A } \\
0 \\
1\end{array}$ & $\begin{array}{c}0.8217 \\
-1.043 \\
-.062 \\
.211 \\
.3419 \\
-.181 \\
-.08\end{array}$ & $\begin{array}{c}N / A \\
0 \\
1\end{array}$ & $\begin{array}{c}0.8707 \\
-.604 \\
.075 \\
0 \\
1.502 \\
-1.223 \\
0\end{array}$ & $\begin{array}{l}0.9681 \\
-.272 \\
-.046 \\
0 \\
-1.001 \\
-1.312 \\
0\end{array}$ & $\begin{array}{l}0.9882 \\
-.237 \\
-.007 \\
0 \\
-.115 \\
-.858 \\
0\end{array}$ & $\begin{array}{l}0.896 \\
-.393 \\
-.028 \\
0 . \\
.0885 \\
.2742 \\
0 .\end{array}$ & $\begin{array}{c}N / A \\
0\end{array}$ \\
\hline
\end{tabular}




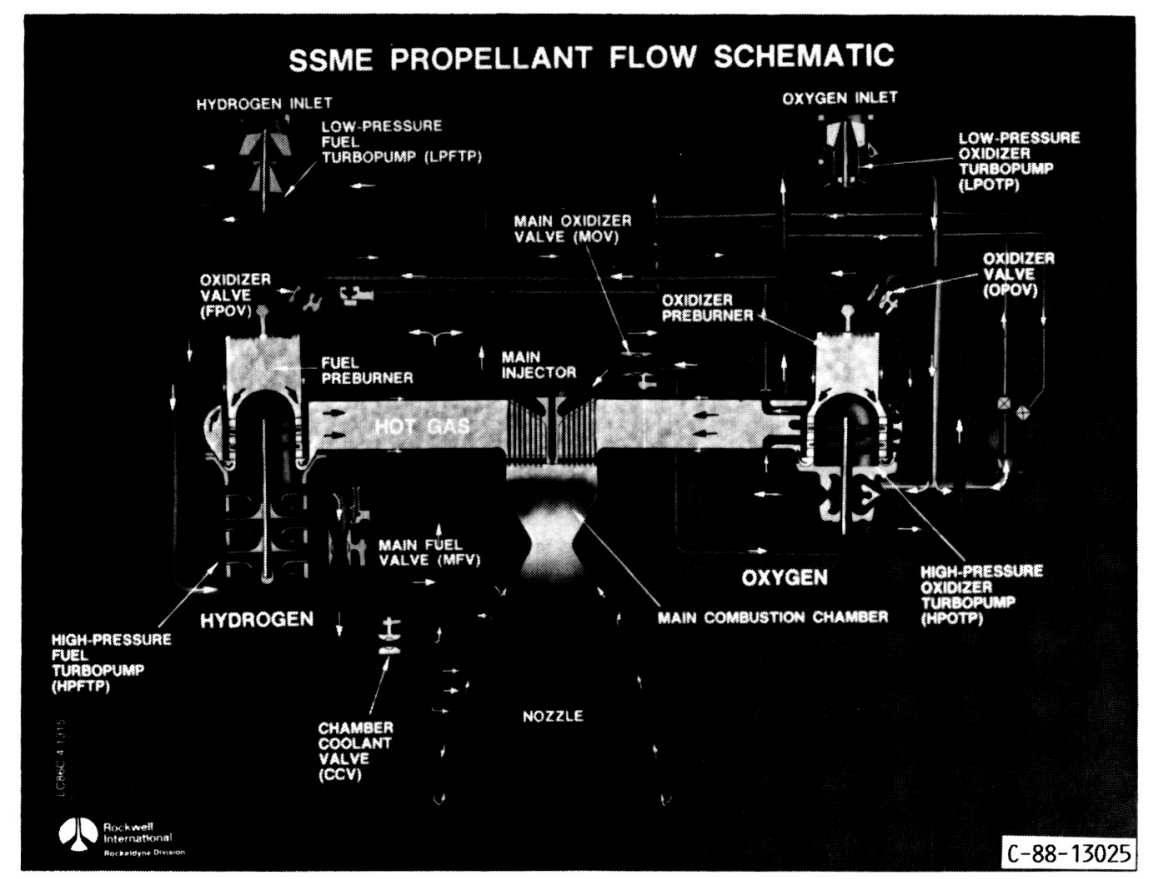

FIGURE 1. - PROPELLANT FLOW AND CONTROL VALVES (ROCKWELL, 1983).

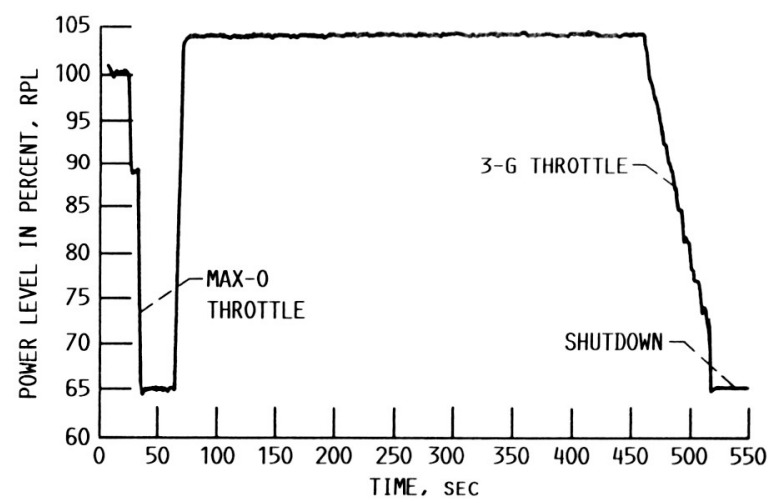

FIGURE 2. - TYPICAL 104\% SSME MISSION (ROCKWELL INTERNATIONAL CORP., 1988). 


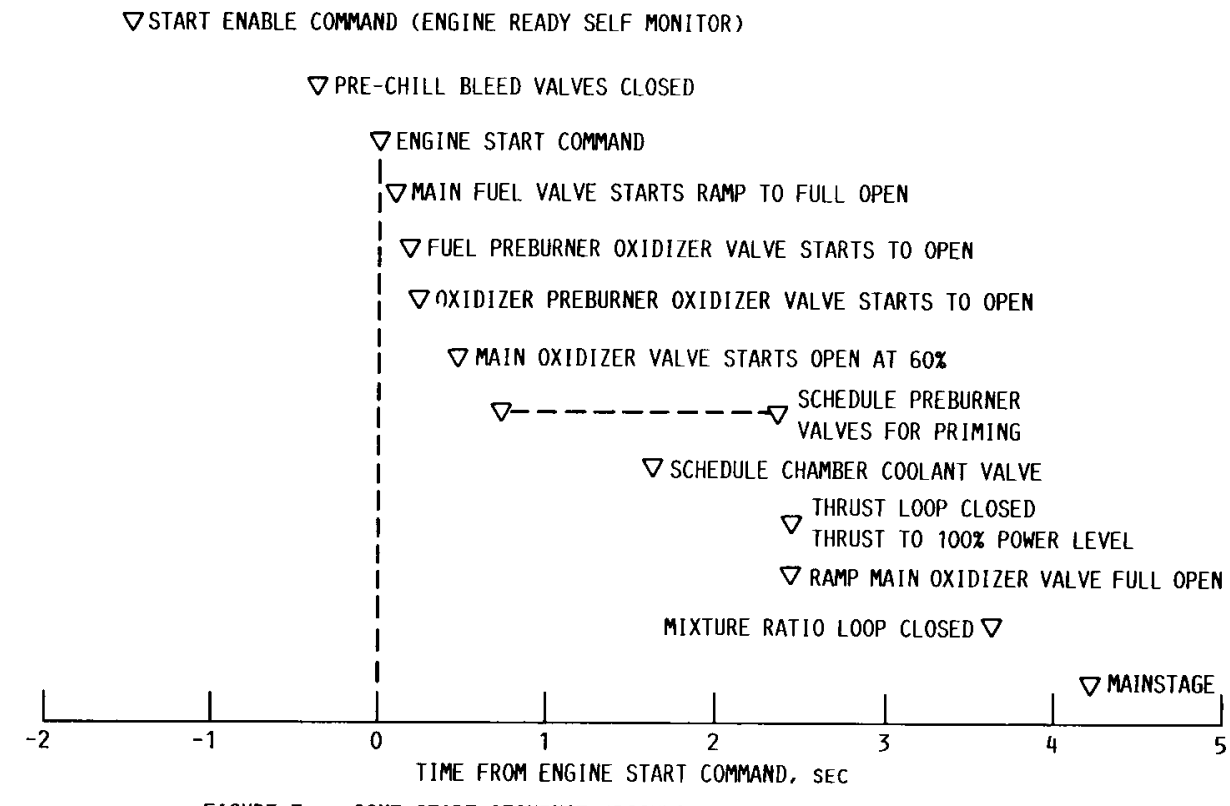

FIGURE 3. - SSME START SEQUENCE (ROCKWELL INTERNATIONAL CORP., 1988).

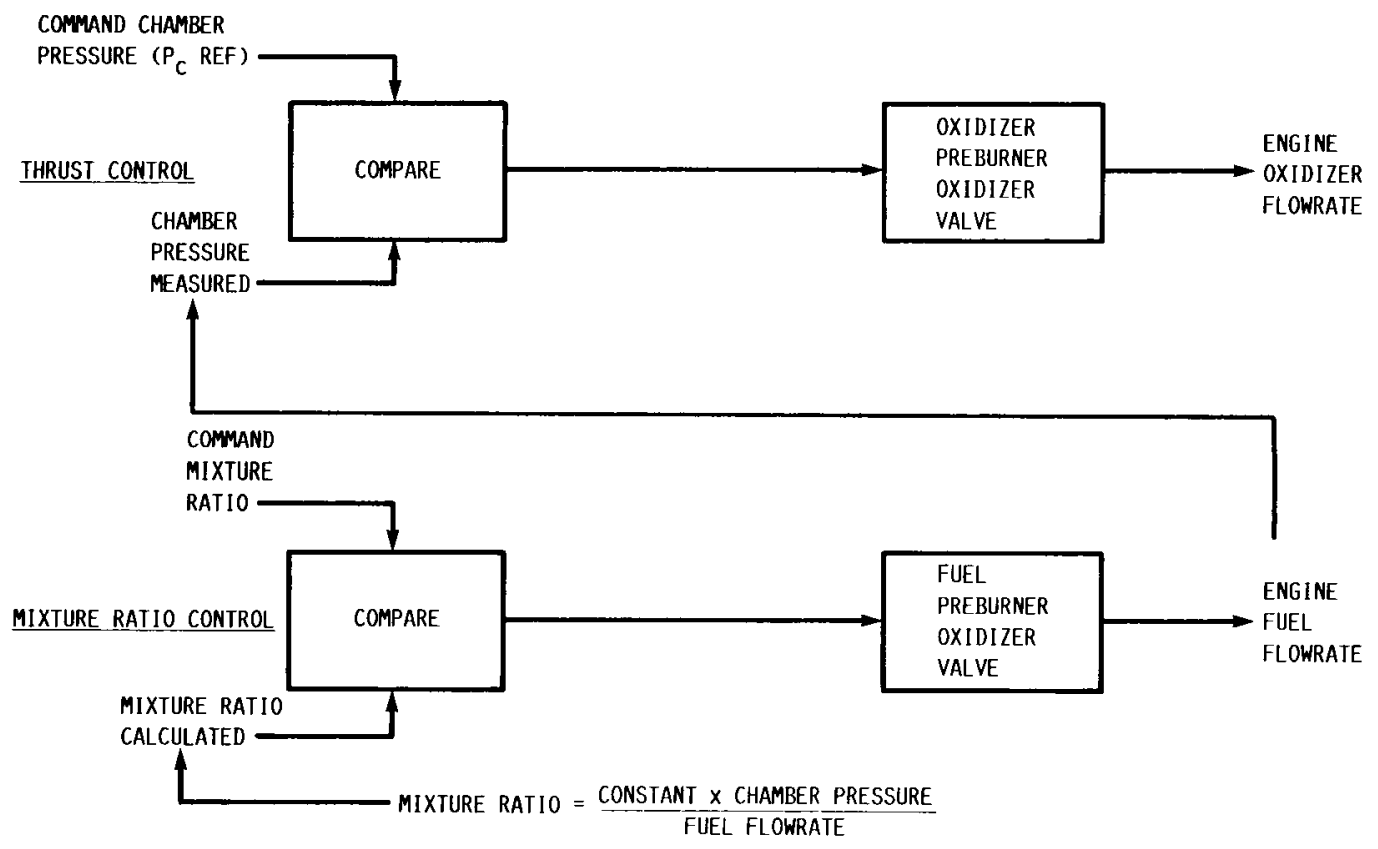

FigURE 4. - SSME PERFORMANCE CONTROL (ROCKWELL INTERNAIIONAL CORP., 1988). 


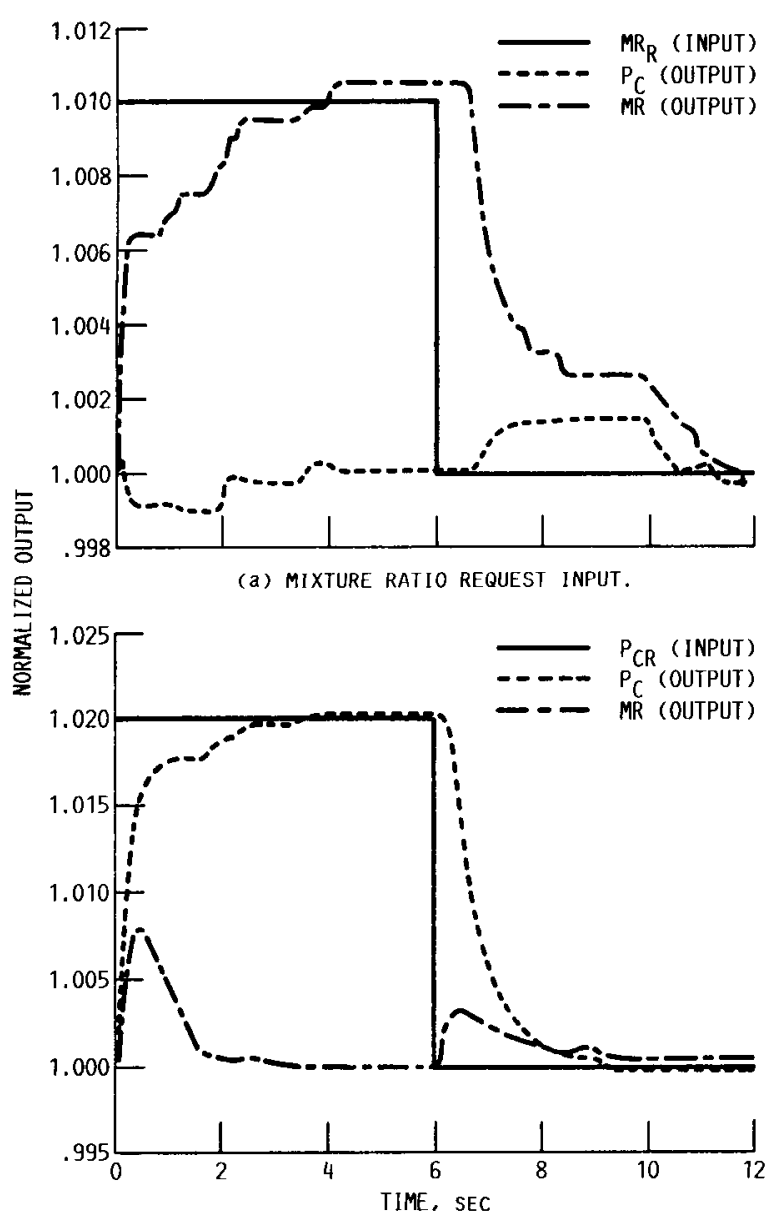

(b) CHAMBER PRESSURE REQUEST INPUT.

FIGURE 5. - SSME CLOSED LOOP RESPONSE.

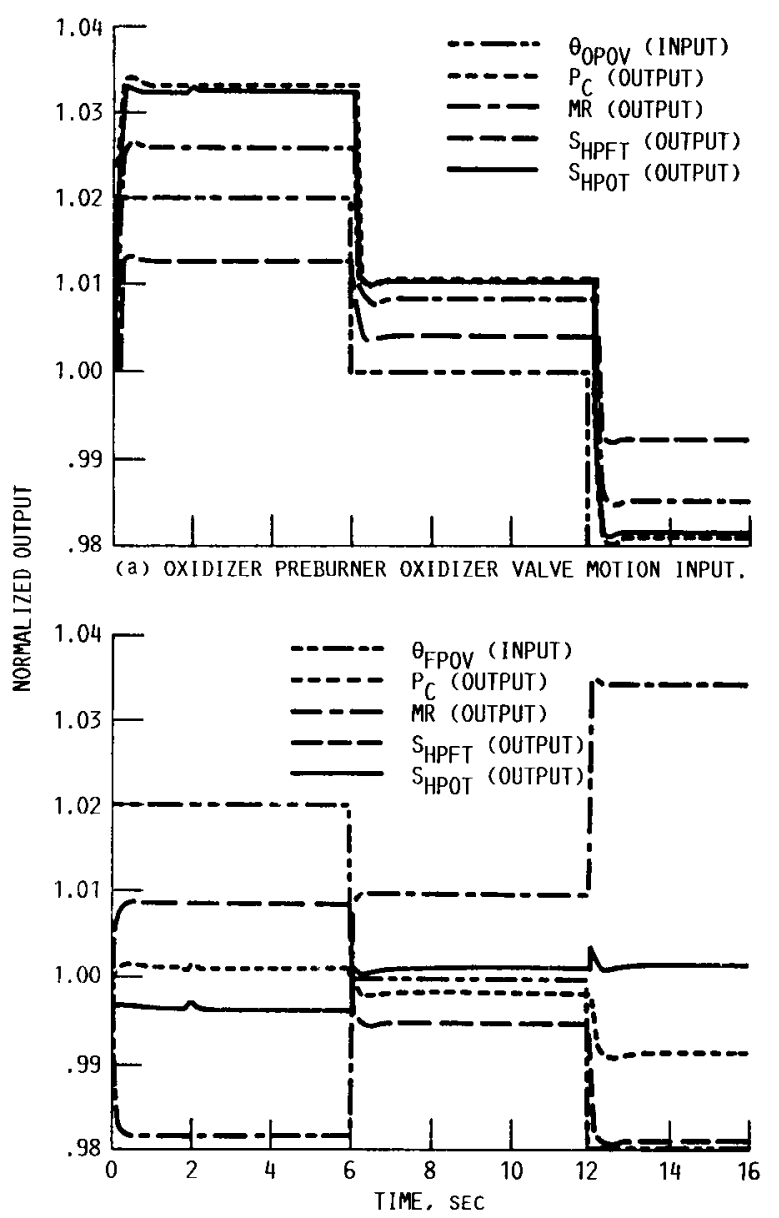

(b) FUEL PREBURNER OXIDIZER VALVE MOTION INPUT. FIGURE 6. - SSME OPEN LOOP RESPONSE. 


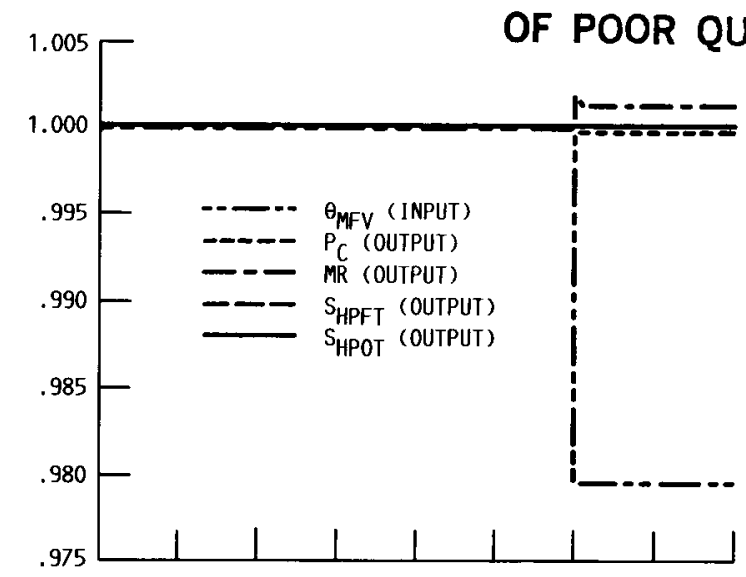

(a) MAIN FUEL VALVE MOTION INPUT.

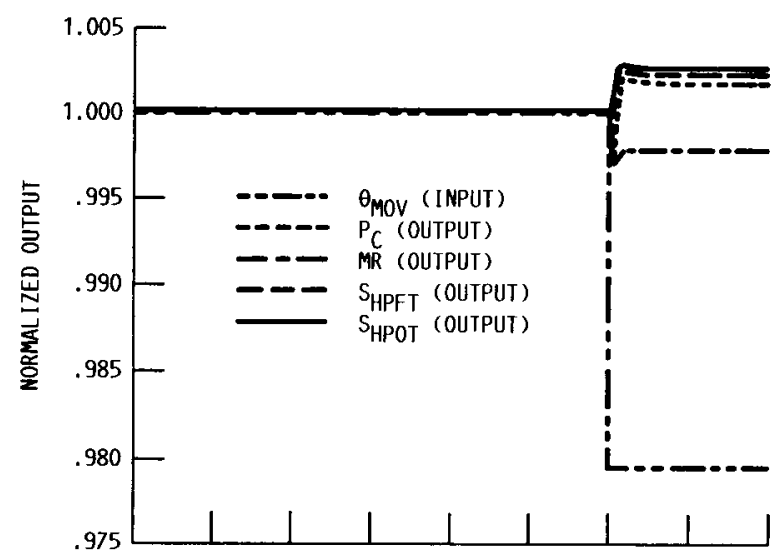

(b) MAIN OXIDIZER VALVE MOTION INPUT.

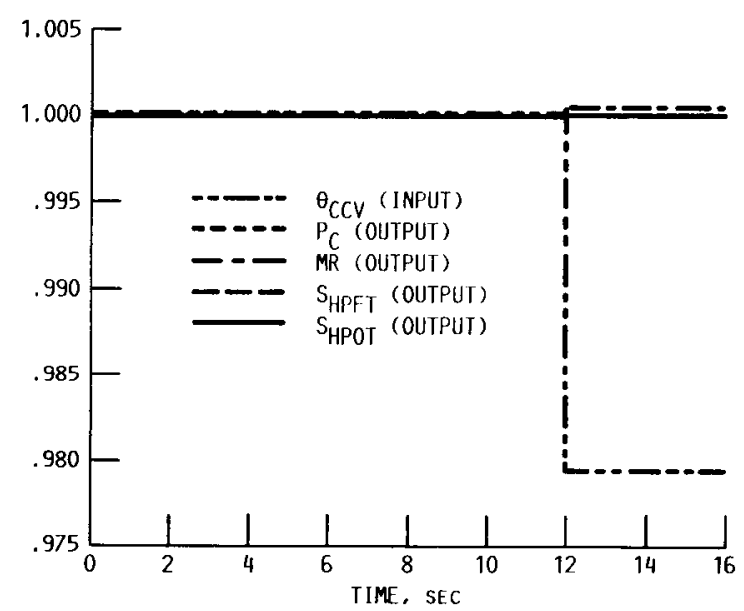

(c) CHAMBER COOLANT VALVE MOTION INPUT,

FIGURE 7. - SSME OPEN LOOP RESPONSE.

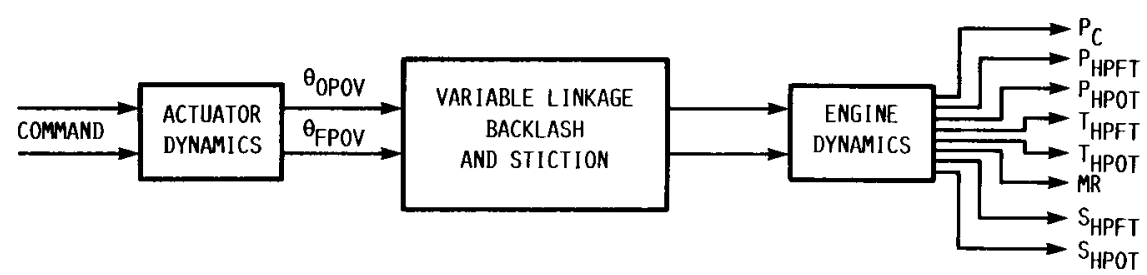

FIGURE 8. - OPEN LOOP SYSTEM WITH ISOLATED VALVE LINKAGE BACKLASH AND VALVE STICTION. 


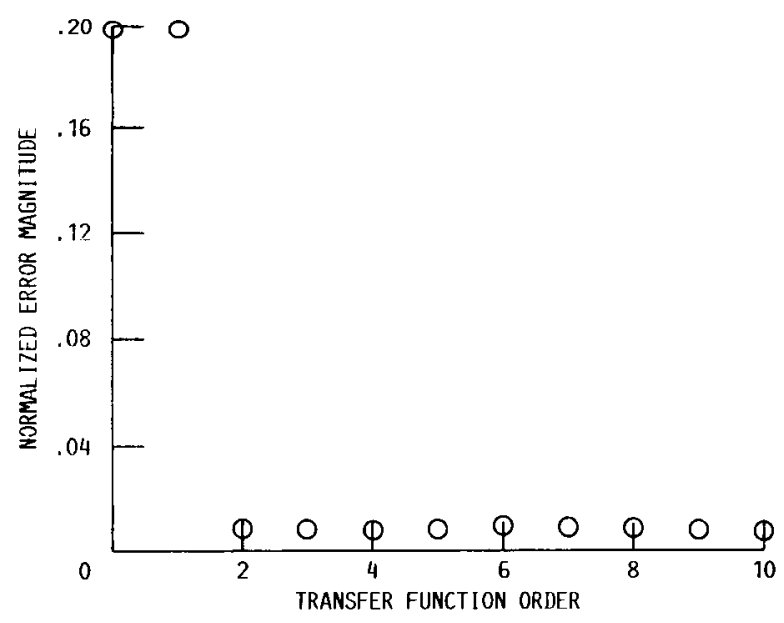

FIGURE 9. - ERROR PLOT. INPUT $=\theta_{O P O V}$ : OUTPUT $=P_{C}$.

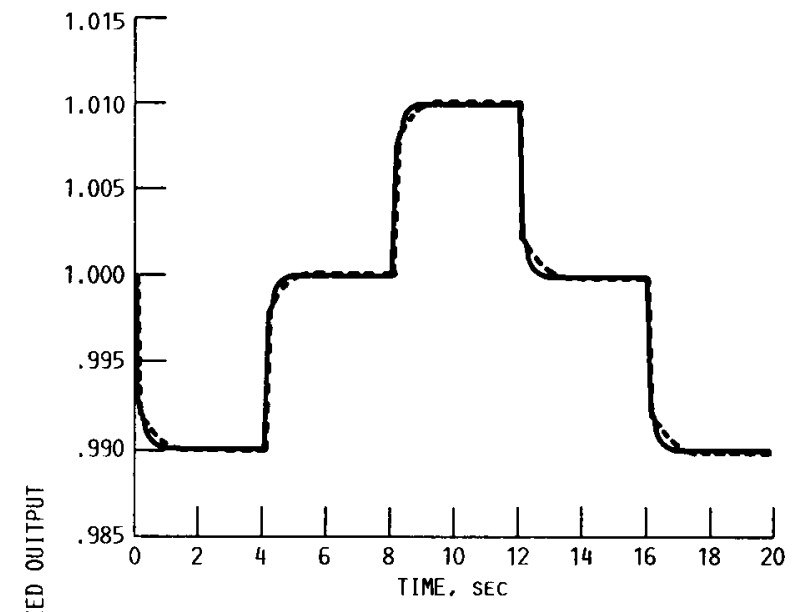

(a) MULTIPULSE RESPONSE.

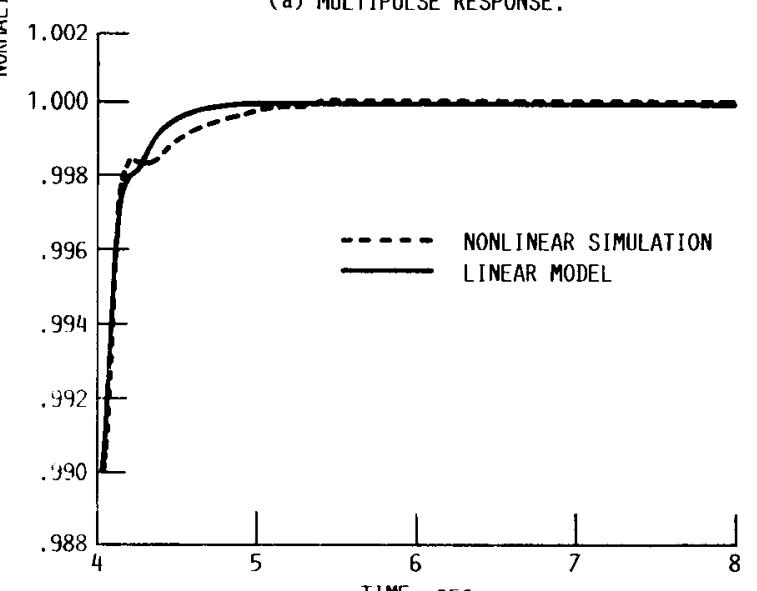

TIME, SEC

(b) STEP RESPONSE.

FIGURE 10. - COMPARISON OF THE RESPONSES OF THE LINEAR MODEL WITH THE NONLINEAR SIMULATION (CLOSED LOOP), INPUT $=\mathrm{P}_{C \mathrm{R}}$ : OUTPUT $=\mathrm{P}_{\mathrm{C}}$. 


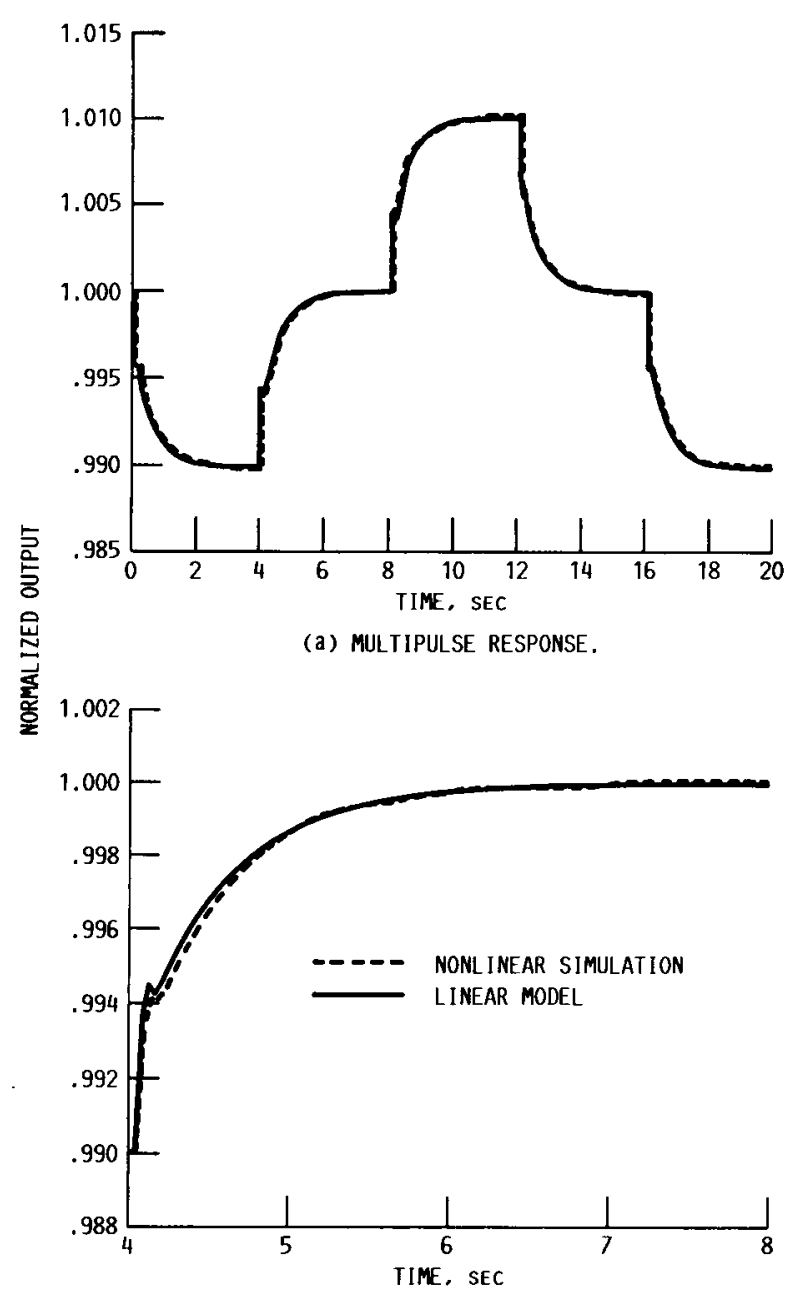

(b) STEP RESPONSE.

FIGURE 11. - COMPARISON OF THE RESPONSES OF THE LINEAR MODEL WITH THE NONLINEAR SIMULATION (CLOSED LOOP). INPUT $=M R_{R} ;$ OUTPUT $=M R$.

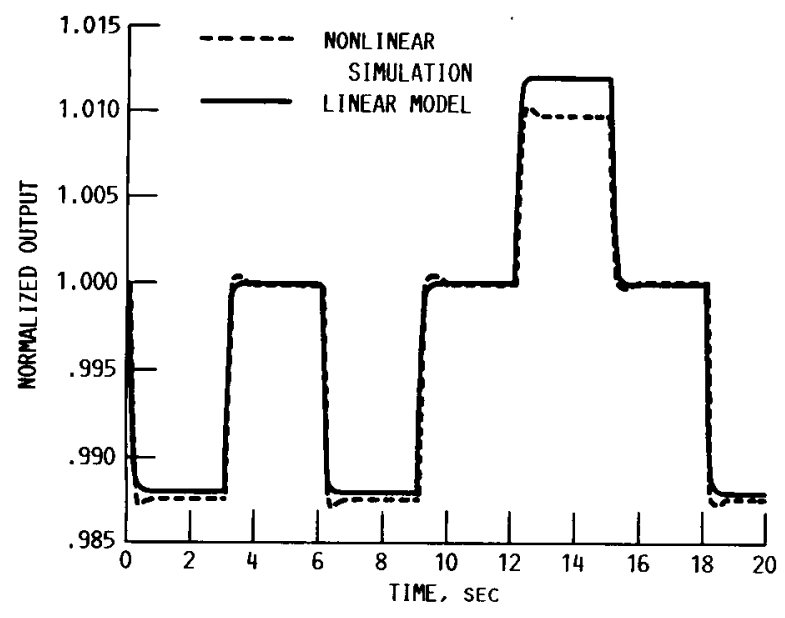

FIGURE 12. - COMPARISON OF THE RESPONSES OF THE LINEAR MODEL WITH THE NONLINEAR SIMULATION (OPEN LOOP). INPUT $=\theta_{\text {OPOV }}:$ OUTPUT $=S_{\text {HPFT }}$.

\section{ORIGINAL PAGE IS
OF POOR Q'A'TrY}

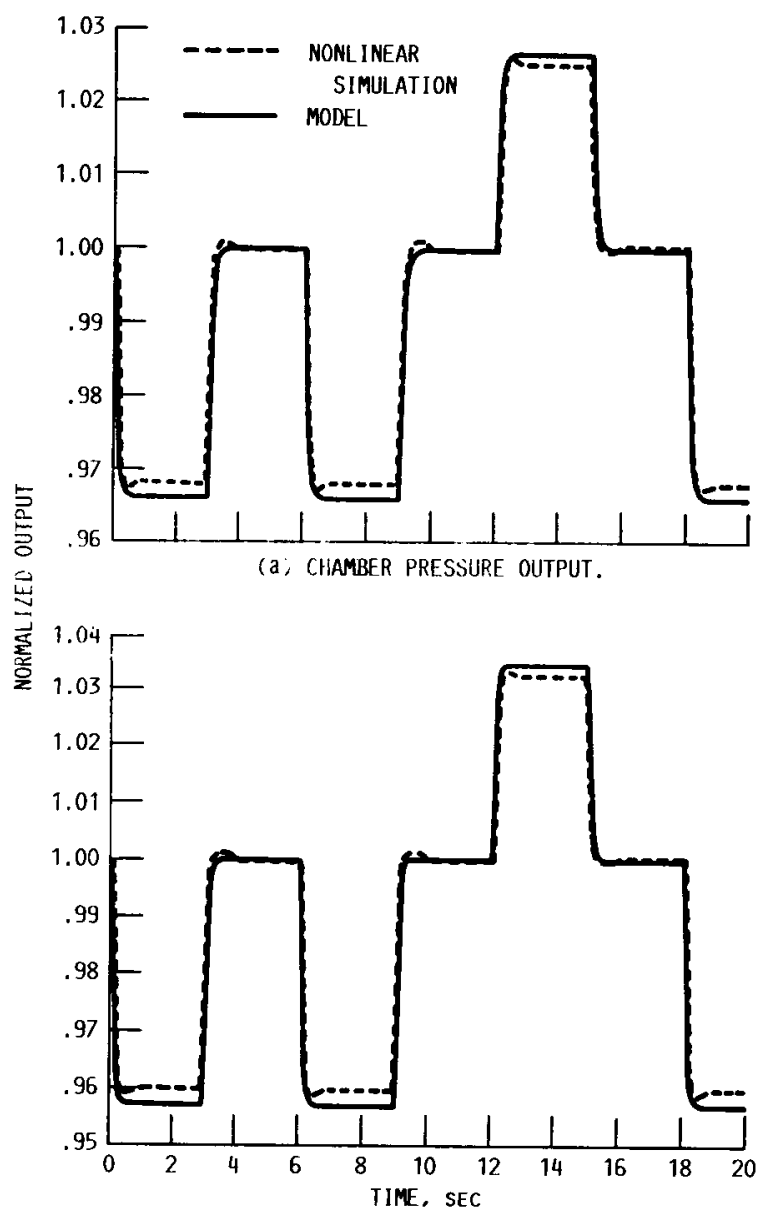

(b) HIGH PRESSURE OXIDIZER TURBINE PRESSURE OUTPUT.

FIGURE 13. - COMPARISON OF THE RESPONSES OF THE IDENTIFIED MODEL WITH THE NONL INEAR SIMULATION (OPEN LOOP). (a) INPUT $=\theta_{O P O V}$; OUTPUT $=P_{C}$. (b) INPUT $=$ $\theta_{\text {OPOV }}$ : OUTPUT $=$ PHPOT $_{\text {HPOV }}$. 

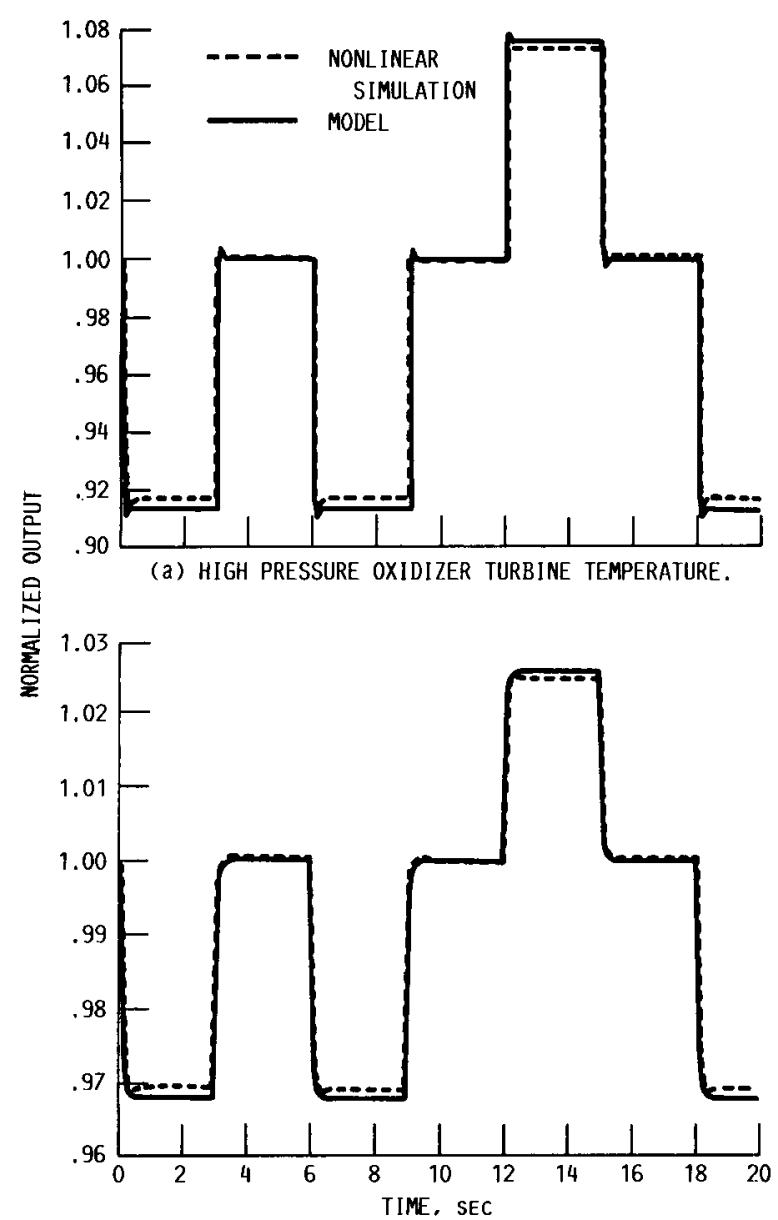

(b) HIGH PRESSURE OXIDIZER TURBINE SPEED.

FIGURE 14. - COMPARISON OF THE RESPONSES OF THE IDENT IFIED MODEL WITH THE NONL INEAR SIMULATION (OPEN LOOP). (a) INPUT $=\theta_{O P O V}$ : OUTPUT $=$

$\mathrm{T}_{\text {HOPT }}$. (b) INPUT $=\theta_{\text {OPOV }}$ : OUTPUT $=\mathrm{S}_{\mathrm{HPOT}}$.
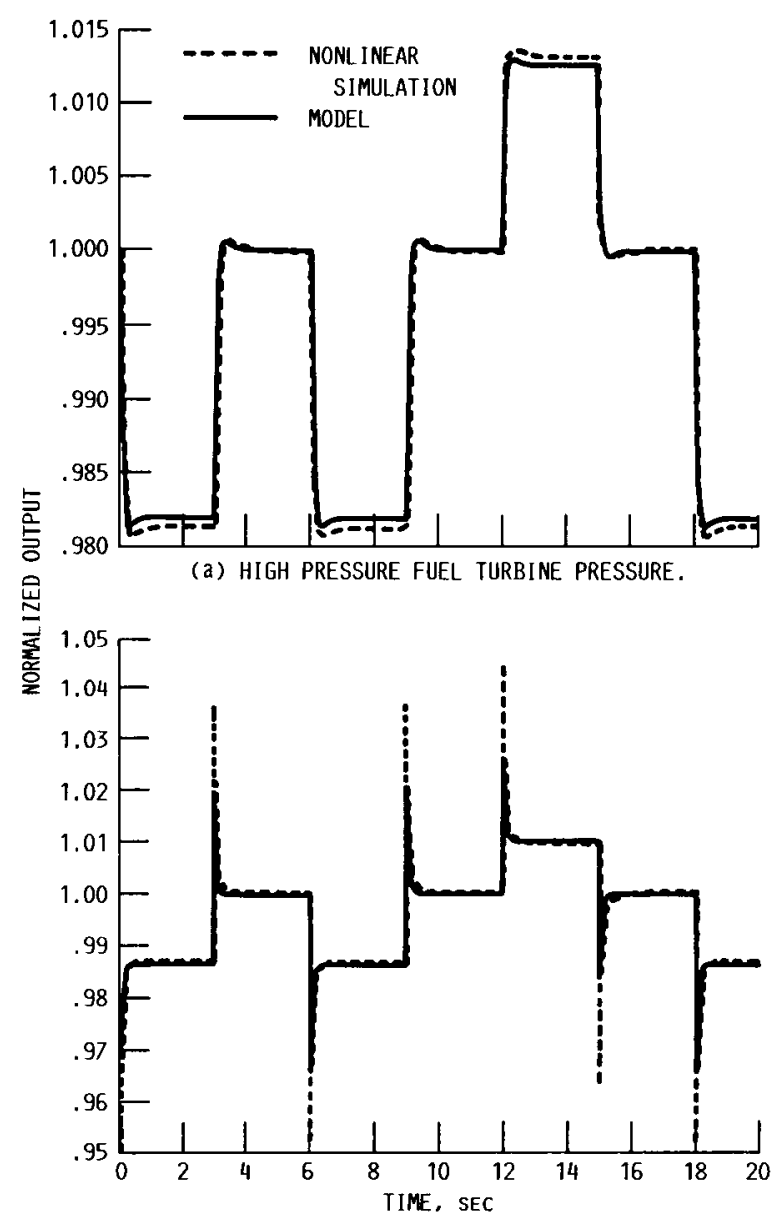

(b) HIGH PRESSURE FUEL TURBINE TEMPERATURE.

FIGURE 15. - COMPARISON OF THE RESPONSES OF THE IDENTIFIED MODEL WITH THE NONL INEAR SIMULATION (OPEN LOOP). (a) INPUT $=\theta_{\text {FPOV }}$; OUTPUT $=$

$P_{\text {HPFT }}$ （b) INPUT $=\theta_{\text {FPOV }} ;$ OUTPUT $=T_{\text {HPFT }}$. 


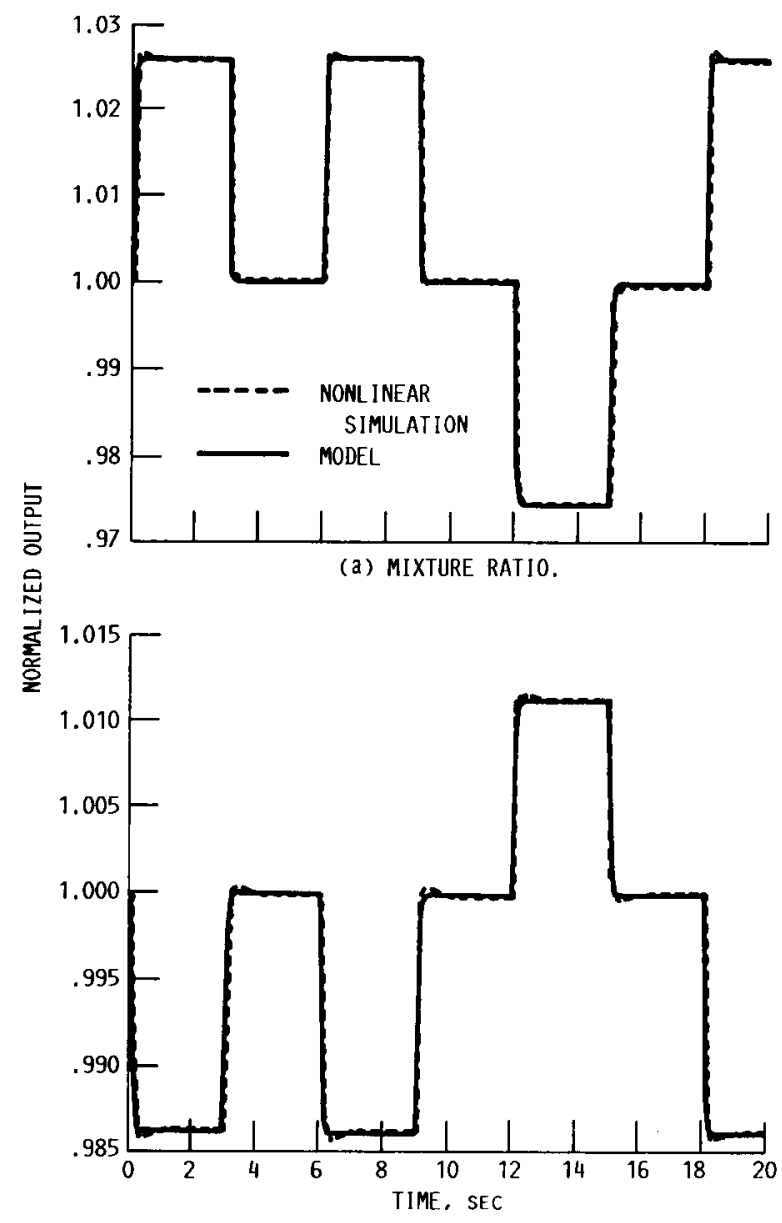

\section{ORIGINAL PAGE IS} OF POOR QUALITY

(b) HIGH PRESSURE FUEL TURBINE SPEED.

FIGURE 16. - COMPARISON OF THE RESPONSES OF THE IDENT IFIED MODEL WITH THE NONL INEAR SIMULATION (OPEN LOOP). (a) INPUT $=\theta_{\text {FPOV: }}$ OUTPUT $=$ MR,

(b) INPUT $=\theta_{\text {FPOV: OUTPUT }}=S_{\text {HPFT }}$.

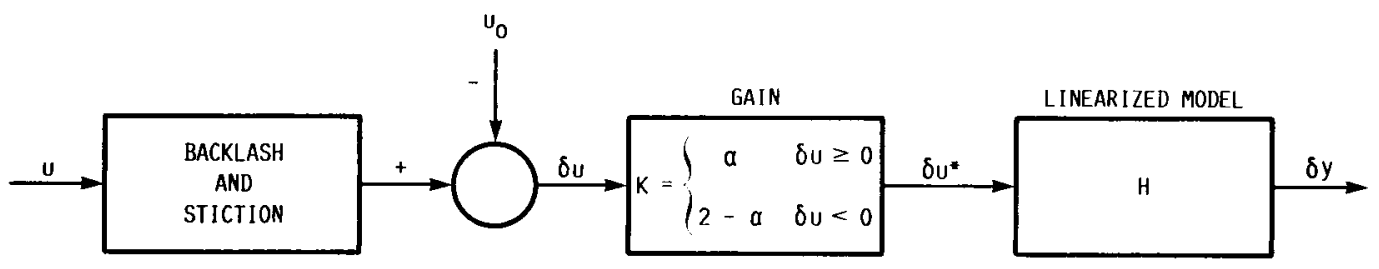

FIGURE 17. - PROPOSED SSME SYSTEM DYNAMICS MODEL AT 100\% RATED POWER. 


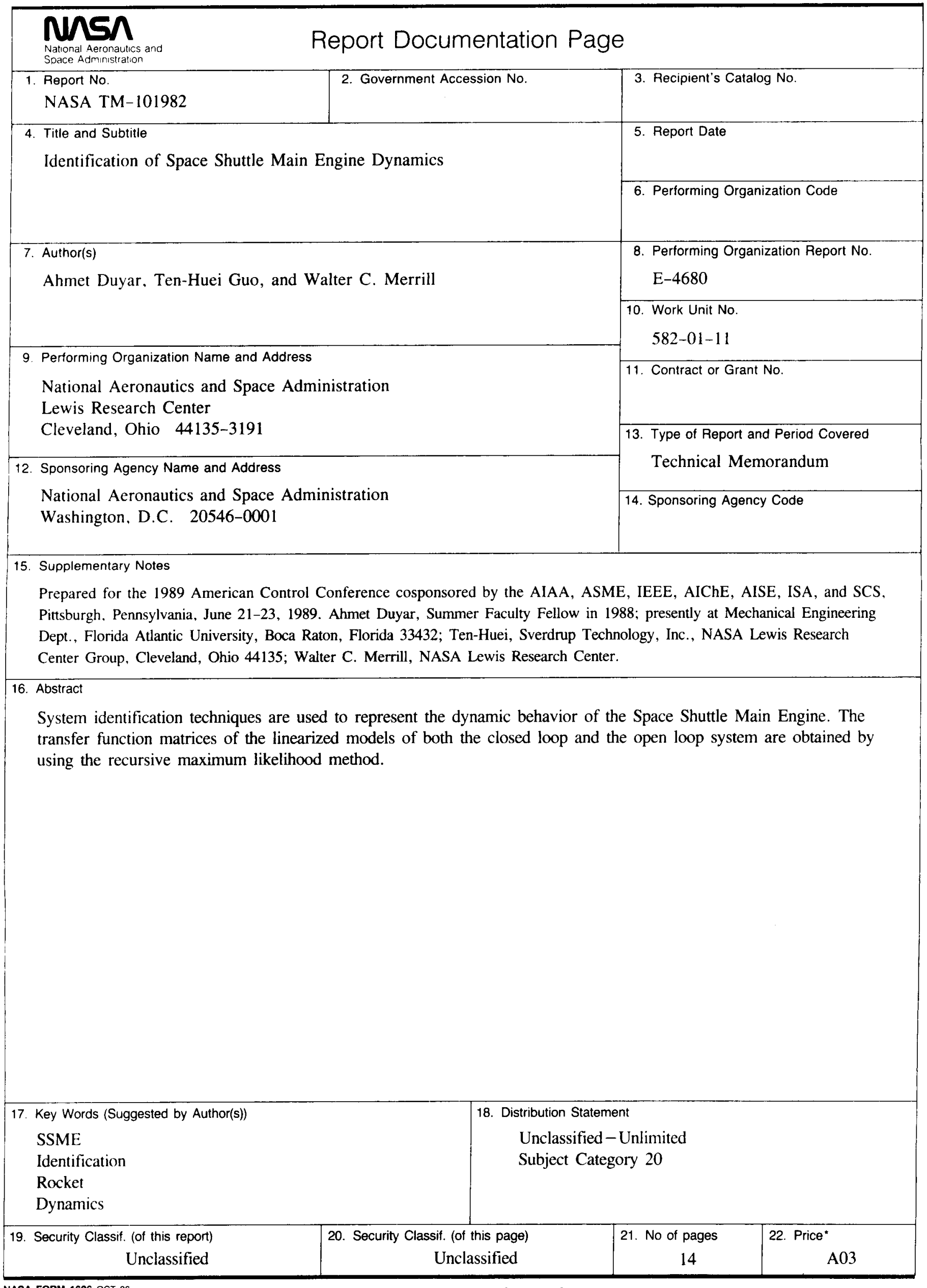

